\title{
CONCEPT OF RECONFIGURABILITY IN INTEROPERATION MANUFACTURING BUFFERS FOR SMART FACTORY
}

doi: 10.2478/cqpi-2019-0077

Date of submission of the article to the Editor: 09/04/2019

Date of acceptance of the article by the Editor: 15/05/2019

\author{
Patrik Grznár ${ }^{1}$ - 0000-0002-0738-8787 \\ Štefan Mozol ${ }^{2}$ - 0000-0002-5536-3306 \\ Vladimír Vavrík ${ }^{2}$ - 0000-0002-4718-5132 \\ Gabriela Gabajová ${ }^{2}$ - 0000-0002-1500-6101 \\ Beáta Furmannová ${ }^{2}$ - 0000-0001-5355-2464 \\ 1, 2University of Žilina, Faculty of Mechanical Engineering, Department of Industrial Engineering, \\ Slovakia e-mail'1: patrik.grznar@fstroj.uniza.sk
}

\begin{abstract}
In this article, it is described how the reconfigurable inter-operational buffers system built on the Digital Twin platform. Interoperating production buffers are now widely used in production. Their effect on the production system can be seen in decreasing downtime. From a cost-based point of view, the interoperating production buffers may generate a gain from the reduction in the volume of work-in-process, with which we increase production performance. This ratio depends on the average number of products that the buffers contain. The average number of pieces in the buffer is limited by the capacity of the buffer. The impact of turbulence in production is seen precisely on the average content of inter-operational production buffers. If we want to maintain work-in-process on optimal values, it is necessary to calculate and maintain the optimal capacity of each interoperating production buffer on the line. In the context of Smart Factory, it is currently possible that the current capacity of the interoperating production buffers is maintained according to the current state of production. In the subject system, real production facilities communicate with each other through the loT as autonomous agents, which are decided on the basis of a formula to calculate the optimal capacity of the buffers, the prediction of faults and negotiation, thus actively maintaining the optimal capacity of intermediate operating production buffers for Smart Factory support.
\end{abstract}

Keywords: Smart Factory, Smart Manufacturing, interoperating production buffers, agent control, reconfigurability

\section{Introduction}

Interoperation manufacturing buffers are an important part of production lines and systems. Their task is to create a stock of spatially oriented parts. The operation of automatic lines is adversely affected by a fixed link between the automats. The tacts of all these automats, in other words, the time to perform a manufacturing operation on 
one product, should be the same. And it is here that there is a contradiction between the requirements of production technology and the time. Thus, if we look at the automatic link from the point of view of failure, failure of one automaton will cause the whole line to be shut down during its repair. The benefits of such a fixed engagement will include, in particular, less area stoppage in relation to product shipments between operations (Ristvej et al., 2018). This will lead to shorter production times and less workin-progress. In a complex logical view, together with the assessment of technological and manufacturing factors, the lack of this involvement leads us to include buffers among some automats (Dulina et al., 2003). If the buffers are automatic, then the entire automats system can be called an automatic line with a flexible link or a flexible automatic line. Each interoperation buffer can be characterized by its capacity, that is, the maximum number of parts that the buffer can take. Depending on the disturbances, the automation system with inter-operation buffers interacts with each other in the operation of the automats. It is stimulated by insufficient supply or removal of semifinished products from buffers (Bubeník and Horák, 2014). In the line connection with $\mathrm{N}$ automats, each automat can be characterized by the intensity of failures, the intensity of maintenance, and the production tact. The running and repair times of the automats are predictable with current options. It is the possibility of analyzing historical data to derive correlations and then comparing the current state with correlations to create a buffer system that is reconfigurable according to the current situation in production. In order to do this, the production data must be sensed by sensors. This data can be applied to a digital twin of automats and buffers to make a digital copy of it (Yang et al., 2018). The digital twin has the decision criteria on which to decide what action to take. It has the ability to communicate with other system agents and, after evaluating the current situation, issues a control command to the real device it represents (Gregor, Groumpos et al., 2017). Reconfiguration is an area that is part of Smart Manufacturing, where production is able to change its capabilities and functionality according to current conditions. At the same time, Smart Manufacturing can be understood as a part of Smart Factory, where all production elements are integrated into one unit. Smart Factory uses Internet of Things technology (IoT) to communicate. Smart Factory is characterized by a constant process when important data is processed and on the basis of which there is a constant optimization of equipment and process parameters (Gregor, Krajčovič et al., 2017). The parameters are adjusted to ensure optimal material flow with the possibility of rapid change of functionality, capacity at minimum cost. In Smart Manufacturing, the low level of production is one of the indicators that shows system efficiency (Jankalová and Jankal, 2018). The production volume is significantly affected by the average stock level stored in the interoperation buffers. By reducing work-inprogress, we contribute to a decrease in the cost of poor quality as well as the costs associated with the volume of parts stored in the buffers. The reduction in the quality of the part is reflected in the lower number of parts deteriorated due to the operation of the conveyor system as well as by the operation of the mutual impression. Lower workin-process can reduce the number of scraps parts produced by poorly set up production facilities. The content of this article is a design of a system for optimizing the capacities of stock buffers in Smart Factory by means of agent reconfiguration of storage capacities suitable especially for lines with different tact settings. 


\section{Definition and manufacturing problem analysis}

Intelligent sizing capacity is closely linked to Smart Factory development. In the future Smart factories in which communication between devices will take place in real time will form one with communication entities just the buffer and conveyor (Kolarovszki and Vaculik, 2014). Based on their information, it will be possible to maintain the system at all times optimum work-in-process that is different for each product. With their function, buffers contribute to reducing downtime by accumulating product stocks in front of the automats. This causes higher costs of poor quality and completion. If the previous workstation fails, then the stock is released and the line is not ideally stopped. It is not possible to install such buffers everywhere so that the line moves in a synchronous way, it is possible to create a minimum stock (Krajčovič and Plinta, 2013). These are mainly transfer lines, assembly rotor automats and a series of assembly stations with a sliding portal, etc. The installation of storage buffers is particularly suitable when it is possible to move the product asynchronously. Asynchronous tacts are characterized by different hight where the highest value tact defines line tact (Gašová et al., 2017). The problem of the high degree of completion arises mainly from the workplace with the highest tact. This creates bottlenecks in production (Wolniak et al., 2018). Pieces of products will accumulate and overwhelm the system. It is appropriate to keep the system as low as possible to eliminate such unjustified high stocks. Reducing work-inprogress will minimize mean lifetime and stock costs. The ideal value of work-inprogress is the point at which mean lifetime, storage costs and downtime are as low as possible (Bubeník, 2004) figure 1.

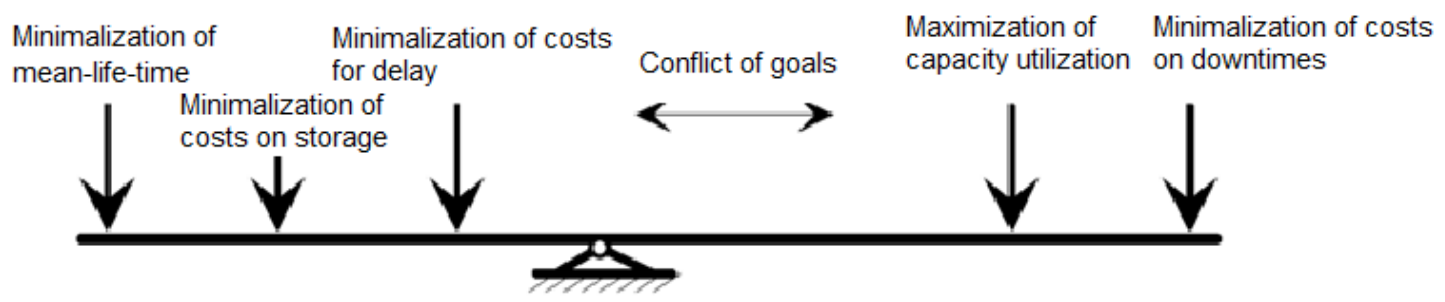

Fig. 1. Conflict of goals in production

Thus, the solution to the optimum stock level in a buffer is a task that can be included in a known relationship of production control dilemma. The aim of the article is to design a system that can dynamically respond to changes in the manufacturing system.

\section{Material and methods}

There is currently no formula to calculate optimal buffer capacities. However, each production buffer capacity creates costs or benefits for the system. Their interaction is expressed by a purposeful function. This can both take a negative and positive value. The optimum capacity of the production buffer can be determined by means of maximum gain or function. The methods of calculation include the Maixner solution of the purpose function (Maixner, 1980).

Maixner's calculation of purpose function - The optimum capacity of the buffers is determined by finding the highest purpose function. In the purpose function Equation (1), the revenue from increased production is taken into account compared to the current solution or transfer production line, the cost of stock and the buffer itself.

$$
G=\left(D . v-\sum_{i=1}^{N-1} Z_{i} \cdot b_{i}\right) \cdot s . w-\sum_{i=1}^{N-1}\left(a_{i} \cdot c_{i}\right) * Z_{i}^{r}
$$


Where:

$\mathrm{G}=$ objective function (unit $€$ )

$\mathrm{v}=$ profit from one product (unit $€$ )

$D=$ increase of performance on the line from the current production or fixed bound line (unit Pcs./2 shift)

$\mathrm{Zi}=$ capacity of $\mathrm{i}$-th buffer (unit Pcs.)

$\mathrm{bi}=$ operating and maintenance costs $\mathrm{i}$-th buffer referenced on one piece and two shifts (unit €/Pcs.2 shift)

$\mathrm{s}=$ number of working days in year

$\mathrm{w}=$ number of years how long will be product made on a line

$\mathrm{ai}=$ production cost per piece of capacity of $\mathrm{i}$-th buffer (unit $€ /$ Pcs.)

$c i=$ Cost of medium and general repair referenced per piece (unit $€ / P c s$.

$r=$ coefficient of growth providing costs and repair costs $(r \geq 1)$

\section{Design of manufacturing buffer reconfigurability system for Smart Factory}

The system for intelligently optimizing buffer capacity will be designed for factories in which information on the real state of production is transformed into necessary decisions. Under decision is understood a command to reconfigure the capacity of the inter-operation storage in buffers and the automation tact's to reduce downtime, Figure 2 illustrates this process.

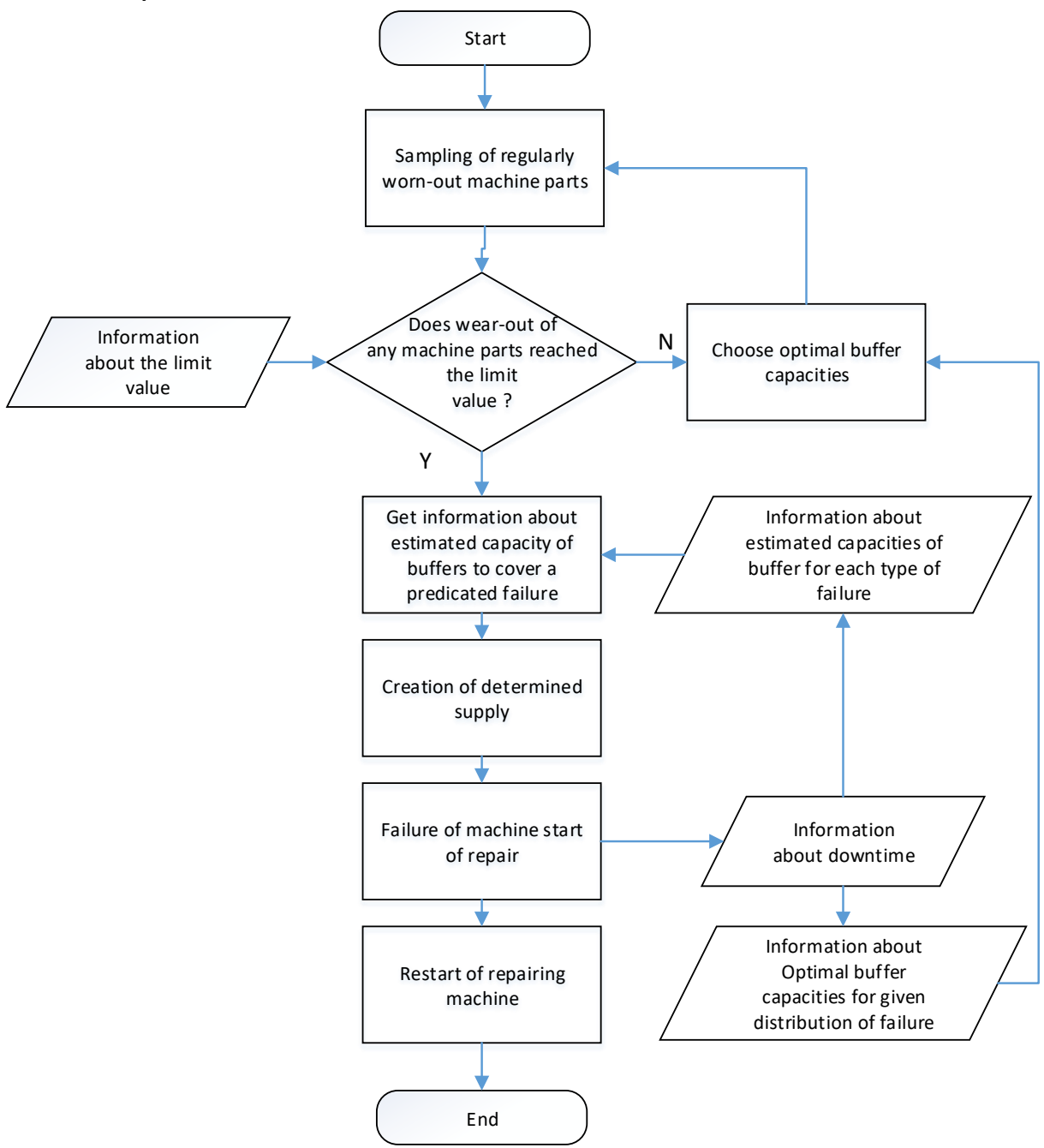

Fig. 2. Process of reconfigurability of manufacturing buffers 
Smart Factory is based on current as well as historical data that is analyzed and based on which control commands are issued. Data that is scanned and processed in real time is the basis for choosing the right decisions (Mičieta, Edl et al., 2018). Historical data is important in terms of predicting future conditions that have occurred in the past. Algorithms referred to as Smart Data will search for invisible links in the data, and predictions and decision support are allowed (Mičieta, Durica et al., 2018). Thus, the final control command is issued based on the current state and the prediction of the state that may occur, and the occurrence of which is based on past state events.

With controlled production based on historical and current data, capacities become dynamic transformations. In conventional manufacturing systems, if the capacity control of the containers is also approached, so the capacities are static. This means that the capacity of the buffers is limited only by weight or volume constraints (Mleczko and Dulina, 2014). In Smart Factory, capacities in buffers are not static but dynamic (Mozol, 2018). Reconfiguration requires that the capacity and functionality of the stacks be changed in real time. That means it is necessary to install sensor support which ensures maintenance of the commanded buffer capacity. The dynamics of stock in the buffer can be seen in the development diagram in figure 3.

a.
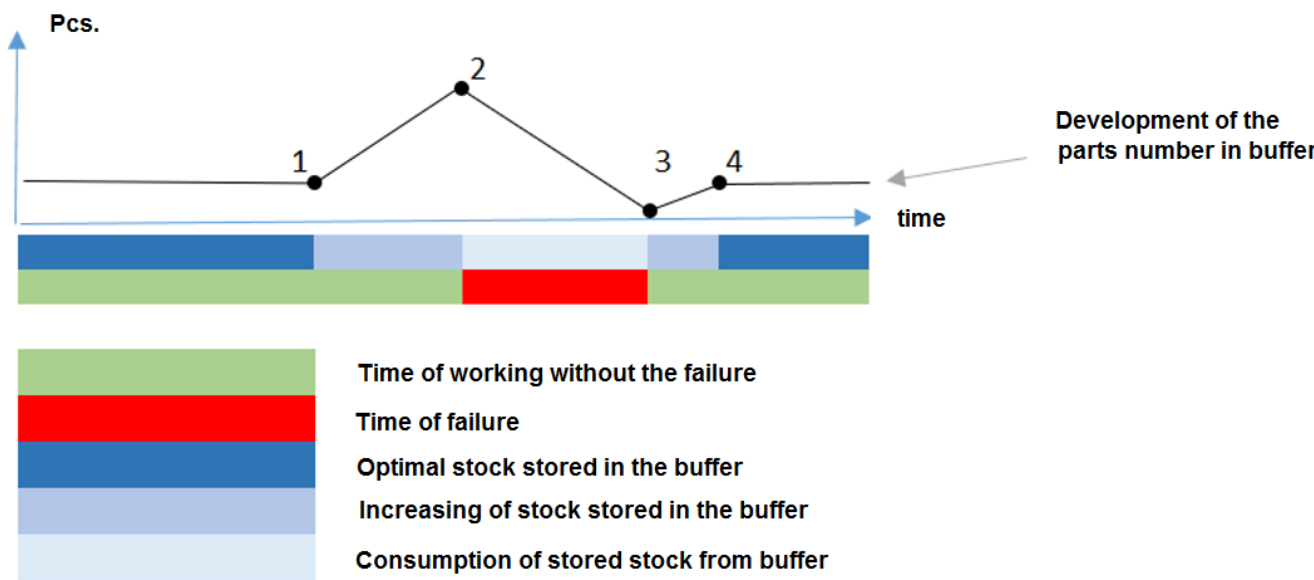

Fig. 3. Graphical expression of the development of stock in reconfiguration able buffers

Figure 3 shows the change in the state of the reconfigurable manufacturing buffer. Point a. represents the number of pieces stored in the buffer. Next b. represents 3 states that set the buffer state (constant optimum, increasing, decreasing). Two machine states are shown in line c. Point 1 represents the point in time at which the automat Ai tact is increased, as well it is a cutoff point. If the stock did not increase, the capacity would not fully cover the downtime. At point 1 , there was optimal capacity in the buffer. This point or time is predetermined on the basis of sensor data, from where it is possible to monitor the time to failure or the need for component replacement. The system knows at what point in time the nearest fault will occur and on its basis and based on the time it takes to repair or maintain the required capacity. Point 1 also represents the moment when the new capacity is set to the buffer. Point 2 represents the point at which the failure or maintenance intervention occurred and no further increase of the buffer stock status is possible. From point 2 to point 3 , there was a gradual consumption of pieces by automat behind the automat $\mathrm{Ai}+1$. In point 3 , the repair was completed. If possible, the Ai will try again at a faster tact than the automat $\mathrm{Ai}+1$. And when it does, in point 4 , it synchronizes its tact with automaton $\mathrm{Ai}+1$ until the time link to point 1 that start 
the whole process again. If automat $\mathrm{Ai}+1$ fails, Ai does not attempt to overproduce, but again tries to optimize the capacity of the buffer. And when it reaches the machine it stops. However, if it indicates a failure of one of its components, it can create supplies in the stock to cover the fault. In order to achieve reconfiguration, data background is necessary. The following figure 4 illustrates this process.

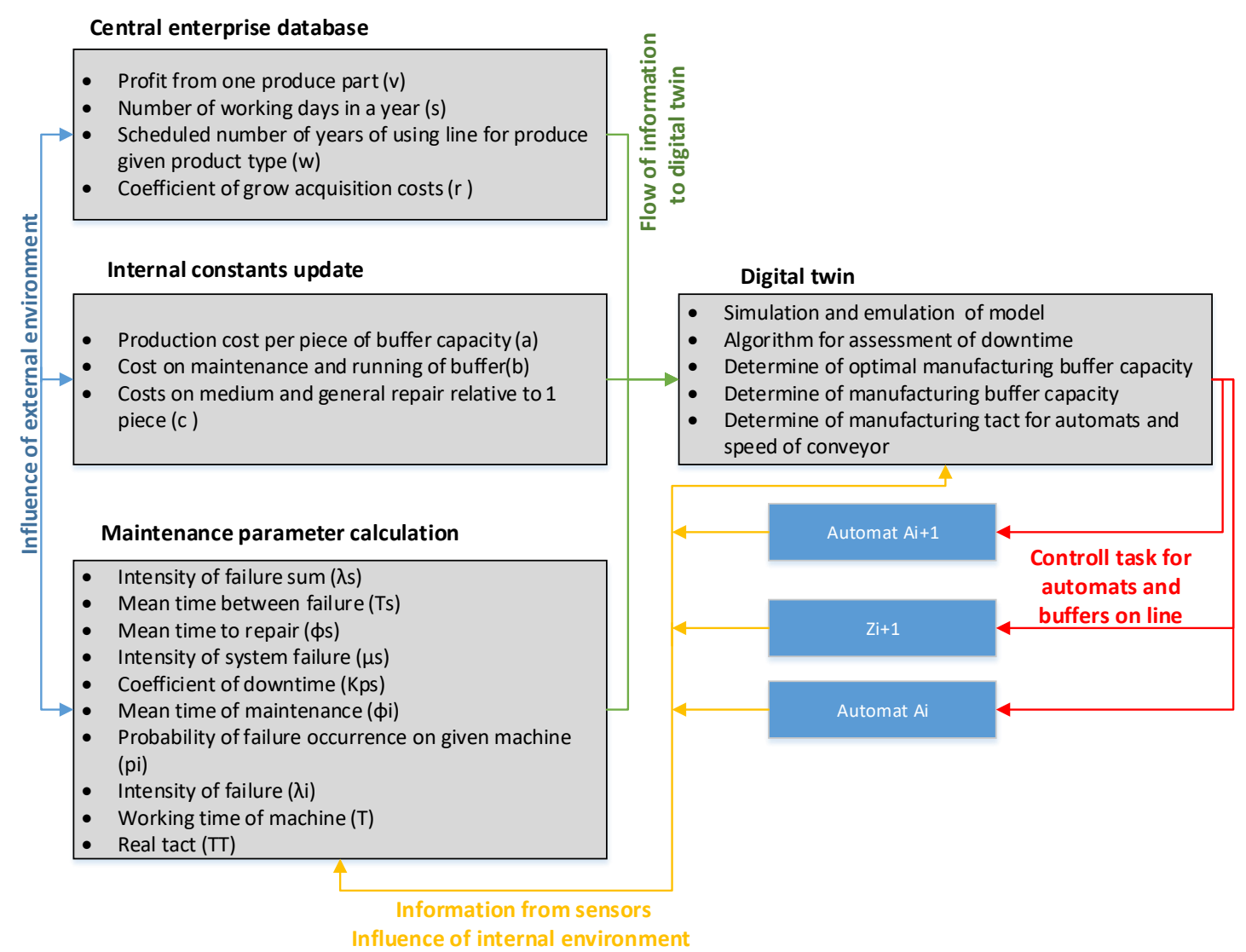

Fig. 4. Exchange of information for reconfiguring manufacturing buffers capacities and individual modules

Central enterprise database block - The database stores information related to product information as the amount produced for the scheduled period, product profit as well as labour and working time fund information and also cost increase coefficient. Their height is affected by the turbulence from the external environment.

Internal constants update block - The block accumulates information that is updated not only based on external environmental stimuli, but also the internal cost history of the manufacturing buffers.

Maintenance parameter calculation block - The maintenance parameters and characterization parameters required for simulation, emulation, and calculation of the optimum buffer capacity are calculated in real time for each automat within the block.

Digital twin block - All previous blocks and sensor information form digital twin parameters. Based on the decision algorithms that take place within the digital twin, emulation, prediction of faults, and issued decisions are made by device commands for manufacturing buffer capacity as well as a command for automat on or off.

This process of mutual communication is made possible by the use of sensors and the processing of information that is transformed into digital copies of twins. Such a digital twin has all the properties of a real object and it is possible to work with such an object in a digital environment. Not only can we simulate different decisions, but also evaluate 
and manage the entire system. At the same time, digital twins can interact with each other and make their own decisions if allowed by program or priority rules or algorithms. Digital twins communicate with their real devices, which they reflect and assign to them. If the whole process is working, it is possible to keep the stock constantly producing the minimum downtime at the optimum cost of production. A byproduct of intelligent tact processing is the decrease in utilization seen on production facilities and reduced energy consumption. There is a direct proportion that if the work-in-progress is reduced, it is reflected in the free capacities of some automats. This negative effect cannot currently be removed without setting the production equipment. However, in the context of reconfigurable manufacturing systems in the future, it will be possible to intelligently reconfigure these automats to reduce free minutes in a product-related product line with proper spatial layout and conveyor bonding, together with a pre-defined CNC or abrasive program. However, even if it is not possible to remove these free minutes, it can be said that the running costs of the equipment are reduced because the equipment in operation has a higher energy consumption than in the rest.

\section{CONCLUSION}

With the exponential, today growth of technology, expensive sensors, software, and computing hardware become more accessible, so the introduction of digital twin solutions will become cheaper. Reconfigurability in the buffer area is based on the capture of information from the real production of their processing and the issuance of logical commands to control units. The control units then adjust the tact on the automat so that the condition of the stock on the conveyor and the buffers answers either the optimum calculated state in the buffer or the capacity that maximum covers the predicated downtime. This system is particularly suitable for lines where products are transferred from workplace to workplace in an asynchronous pattern. It is advisable that the equipment on the line should be involved in a certain period of time in order to determine availability, MTTR for a particular type of failure. In this way, we can achieve that we are actively minimizing line downtime while reducing the cost of work-inprocess.

\section{ACKNOWLEDGEMENTS}

This research was supported by the Slovak Grant Agency: KEGA - 020ŽU-4/2019.

\section{REFERENCES}

Bubeník, P., 2004. A scheduling system for minimizing the costs of production. Strojniški vestnik : Journal of mechanical engineering, 50(5), 291-297. ISSN 00392480.

Bubeník, P., Horák, F., 2014. Proactive approach to manufacturing planning. Quality Innovation Prosperity, 18(1), 23-32. https://doi.org/10.12776/QIP.V18I1.208

Dulina, L., Malcho, M., Micieta, B., 2003. Optimal utilization of the employees potention in the manufacturing condition, 14th International Symposium of the Danube-AdriaAssociation-for-Automation-and-Manufacturing, Sarajevo, 129-130. 
Gašová, M., Gašo, M., Štefánik, A., 2017. Advanced industrial tools of ergonomics based on Industry 4.0 concept. Procedia Engineering, 192, 219-224. ISSN 18777058. https://doi.org/10.1016/j.proeng.2017.06.038

Gregor, T., Krajčovič, M., Wiecek., D. 2017. Smart Connected Logistics. Procedia $\begin{array}{llll}\text { Engineering, } & \text { 192, } & 265-270 . & \text { 1877-7058. }\end{array}$ https://doi.org/10.1016/j.proeng.2017.06.046

Gregor, M., Groumpos, P. P., Gregor, M., 2017. Using Weight Constraints and Masking to Improve Fuzzy Cognitive Map Models. 2nd Conference on Creativity in Intelligent Technologies and Data Science (CIT and DS), Volgograd, Russia, SPRINGERVERLAG BERLIN : Communications in Computer and Information Science, 91-106.

Jankalová, M., Jankal, R., 2018. Sustainability Assessment According to the Selected Business Excellence Models. Sustainability, 10(10: 3784), https://doi.org/10.3390/su10103784

Kolarovszki, P., Vaculik, J., 2014. Intelligent storage system based on automatic identification. TRANSPORT AND TELECOMMUNICATION JOURNAL, 15(3), 185195. https://doi.org/10.2478/ttj-2014-0016

Krajčovič, M., Plinta, D., 2013. Adaptive inventory control system for material items with continuous non-stationary demand. Management and production engineering review, 5(1), 1-20, https://doi.org/10.2478/mper-2014-0002

Maixner, L., 1980 Navrhovanie automatických výrobných systémov, SNTL Nakladatelství technické literatúry, Praha.

Mičieta, B., Ďurica, L., Biňasová, V., 2018. New solution of abstract architecture for control and coordination decentralized systems. Tehnički Vjesnik. 25(1), 135-143. ISSN 1330-3651, https://doi.org/10.17559/TV-20160117100949

Mičieta, B., Edl, M., Krajčovič, M., Dulina, L., Bubeník, P., Ďurica, L., Biňasová, V., 2018. Delegate MASs for coordination and control of one-directional AGV systems: a proof-of-concept. The International Journal of Advanced Manufacturing Technology, 94(1-4), 415-431. ISSN 0268-3768.

Mleczko, J., Dulina, L'., 2014. Manufacturing documentation for the high-variety products. Management and production engineering review, 5(3), 53-61. ISSN 20821344. https://doi.org/10.2478/mper-2014-0027

Mozol, Š., 2018. Určenie kapacít výrobných zásobníkov vo vybranom podniku. diploma thesis. Žilina : Žilinská univerzita v Žiline, 2018. 69 pp.

Ristvej, J., Zagorecki, A.T., Holla, K., et al., 2013. Modelling, simulation and information systems as a tool to support decision-making process in crisis management. European Simulation and Modelling Conference (ESM 2013), Lancaster, 71-76.

Wolniak, R., Skotnicka-Zasadzień, B., Gębalska-Kwiecień, A., 2018. Identification of bottlenecks and analysis of the state before applying lean management. 12th International Conference Quality Production Improvement (QPI 2018), Zaborze, Poland, 1-6,

Yang, H.L., Chang, T.W., Choi, Y., 2018. Exploring the Research Trend of Smart Factory with Topic Modeling. Sustainability 10(8: 2779), https://doi.org/10.3390/su10082779 